Supplementary Information

\title{
Ultrafast Photoluminescence from Suspended Gold/graphene Hybrid Structures
}

Gu Yu Zhou, ${ }^{\dagger}$ Xin Ming Ma, ${ }^{\dagger}$ Meng Jian Zhu, ${ }^{\dagger}$ Zhi Hong Zhu, ${ }^{\dagger}$ Ze Lin Tan, ${ }^{\dagger}$ Shi Qiao Qin, ${ }^{\dagger}$ and Ken $\mathrm{Liu}^{\dagger}$

${ }^{\dagger}$ College of Advanced Interdisciplinary Research, National University of Defense Technology, Changsha, Hunan 410073, China 

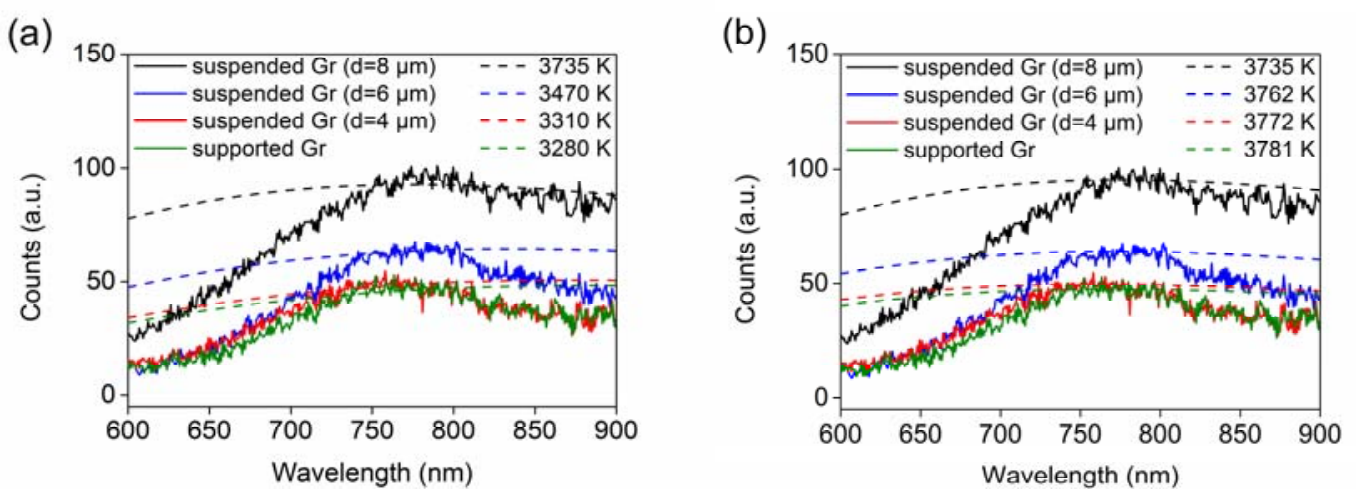

Figure S1. PL of graphene with grey-body radiation fitting. The grey-body radiation fitting is based on the radiation intensity (a) and emission peak wavelength (b). Dashed lines in (a) indicate the grey-body radiation at $3735 \mathrm{~K}$ (black), $3470 \mathrm{~K}$ (blue), $3310 \mathrm{~K}$ (red) and $3280 \mathrm{~K}$ (green), with peak emission wavelength at $775 \mathrm{~nm}, 835 \mathrm{~nm}$, $875 \mathrm{~nm}$ and $883 \mathrm{~nm}$. Dashed lines in (b) indicate the grey-body radiation at $3735 \mathrm{~K}$ (black), $3762 \mathrm{~K}$ (blue), $3772 \mathrm{~K}$ (red) and $3781 \mathrm{~K}$ (green), with peak emission wavelength at $775 \mathrm{~nm}, 770 \mathrm{~nm}, 768 \mathrm{~nm}$ and $766 \mathrm{~nm}$. 